\title{
Investigation of the channel for information transfer by electric, electromagnetic and acoustic waves in layered environment with ice cover
}

\author{
Vladimir Korochentsev ${ }^{1 *}$, Vey Syue ${ }^{2}$, Viktor Petrosyants ${ }^{3}$, Artem $_{E^{2}}{ }^{1}$, Ivan Garasev ${ }^{1}$, Lyudmila \\ Gubko ${ }^{1}$. \\ ${ }^{1}$ FEFU, Engineering school, Department of instrumentation, Russia \\ ${ }^{2} \mathrm{HIU}$, College of underwater acoustic engineering, China \\ ${ }^{3}$ FEFU, Engineering school, Department of electronics and communications, Russia
}

\begin{abstract}
A theoretical model of electromagnetic wave propagation in an ice layer was developed. A half-wave vibrator frozen in an ice layer is used as a receiving-radiating system of electromagnetic waves. Schemes of developed acoustic low-frequency radiators based on electric sparks are described. The possibility of application of the developed systems to receive acoustic signals from earthquake ice source is under discussion.
\end{abstract}

\section{Introduction}

Propagation of electromagnetic and acoustic waves in an ice layer can be used in communication systems, in the investigation of ocean physical characteristics, earthquake and tsunami problems. Classical methods of calculation, for example, normal wave methods require significant computational resources [1, 2, 3, 4]. Systems of operative application of the equipment for communication and control over the processes in the ocean require computational models allowing one to analyze wave fields in layered mediums properly. The paper proposes a mathematical model which makes it possible to analyze electromagnetic field in an ice layer using «directed» Green's functions developed by the authors of this paper $[5,6,7]$. The suggested model us capable of dividing a space into separate surfaces of simple forms as four planes. A boundary problem, taking into account a chosen half-space, is solved for each surface. Applying a linear model, we sum up the fields obtained in each surface. The obtained solutions are approximate but correct in the sense of Jacques Hadamard. Acoustic field is analyzed by the same technique. The aim of the paper is to investigate experimentally the mathematical model of electromagnetic and acoustic wave propagation in an ice layer bounded by air and sea water.

*Corresponding author: ga_i_uzt@mail.ru 


\section{Mathematical model.}

We choose Helmholtz equation as a mathematical model

where

$$
\begin{gathered}
\Delta \mathbf{E}+\left(\omega / \mathrm{c}_{\mathrm{n}}\right)^{2} \mathbf{E}=\delta\left(\theta, \theta_{0}, \mathrm{r}, \mathrm{r}_{0}\right), \\
\Delta \mathbf{H}+\left(\omega / \mathrm{c}_{\mathrm{n}}\right)^{2} \mathbf{H}=\delta\left(\theta, \theta_{0}, \mathrm{r}, \mathrm{r}_{0}\right),
\end{gathered}
$$

$\mathbf{E}$ is the electromagnetic wave strength vector;

$\mathbf{H}$ is the magnetic field strength vector;

$\mathrm{c}_{\mathrm{n}}$ is the phase velocity of electromagnetic wave propagation in ice, water and ground;

$\omega$ is the circular frequency $2 \pi / T$, where $T$ is the harmonic oscillation period;

$\delta(\theta, \theta 0, \mathrm{r}, \mathrm{r} 0)$ is the Dirac delta function depending of distance $r$ and angle $\theta$.

We consider the following problem. We need to calculate the field of a point directed electromagnetic wave source located inside an ice layer (Fig. 1). The following characteristics are known: magnetic and dielectric permeability of air sea and ice.

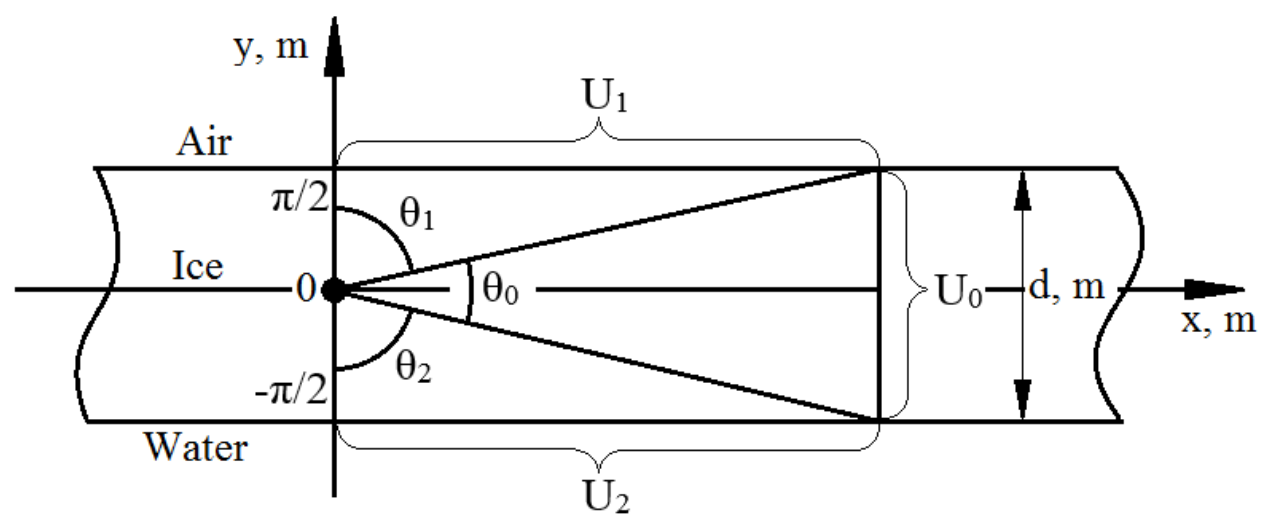

Fig. 1. Geometry of the problem under consideration. 0 - radiation source, $U_{1}-$ variable integrated «ice - air» boundary, $\mathrm{U}_{2}$ - variable integrated «ice - water» boundary, $\mathrm{U}_{0}$ - the boundary showing calculation limit, $\mathrm{d}$ - ice layer thickness, $\mathrm{m}$ - meter (length unit).

Two conjugate Green functions are the solutions of Helmholtz equation.

One of the Green functions $\mathrm{G}_{1}\left(\mathrm{M}, \mathrm{M}_{0}\right)$ describes waves radiating from the radiator surface and the conjugate one $\mathrm{G}_{1}^{-1}\left(\mathrm{M}, \mathrm{M}_{0}\right)$ describes reflected waves [1]. The sum of these two functions is the solution of Helmholtz equation:

where

$$
\mathrm{G}_{\Sigma}=\sum_{\mathrm{l}=1}^{\mathrm{L}}\left[\mathrm{G}_{\mathrm{i}}\left(\mathrm{M}, \mathrm{M}_{0}\right)+\mathrm{k}_{\mathrm{ompl}} \mathrm{G}_{1}^{-1}\left(\mathrm{M}, \mathrm{M}_{0}\right)\right]
$$

$\mathrm{M}$ is the signal reception point with the coordinates $\mathrm{x}$ and $\mathrm{y}$;

$\mathrm{M}_{0}$ is the signal radiation point with the coordinates $\mathrm{x}_{0}$ and $\mathrm{y}_{0}$.

Directed Green function for a point source has the form

where

$$
\mathrm{G}_{\mathrm{l}}=\frac{\mathrm{i}}{2 \pi} \int_{\mathrm{U}_{\operatorname{lmin}}}^{\mathrm{U}_{\operatorname{lmax}}} \frac{\mathrm{F}_{1}(\theta)}{\sqrt{\mathrm{k}^{2}-\mathrm{U}_{1}^{2}}} \mathrm{e}^{\left\{\mathrm{i}\left(\mathrm{x}-\mathrm{x}_{0}\right) \sqrt{\mathrm{k}^{2}-\mathrm{U}_{1}^{2}}+\left[\mathrm{y}(\mathrm{x})-\mathrm{y}_{0}\right] \mathrm{U}_{1}\right\}} \mathrm{dU}_{1}
$$

$F_{l}(\theta)=1$, if $\theta_{l \min } \leq \theta \leq \theta_{l \max }$ when $l=1,2,3, \ldots, l . F_{l}=0$ for other values of $\theta \cdot \mathrm{U}_{1}=\mathrm{ksin} \theta$. 
In the paper, spherical waves are represented in the form of superposition of plane waves, thus, reflection coefficient for plane waves is fair

$$
\begin{gathered}
\mathrm{k}_{\mathrm{omp}}=\mathrm{k}_{21} \mathrm{k}_{23}, \\
\mathrm{k}_{21}=\left(\mathrm{Z}_{1}-\mathrm{Z}_{2}\right) /\left(\mathrm{Z}_{1}+\mathrm{Z}_{2}\right), \\
\mathrm{k}_{23}=\left(\mathrm{Z}_{3}-\mathrm{Z}_{2}\right) /\left(\mathrm{Z}_{3}+\mathrm{Z}_{2}\right), \\
\mathrm{Z}_{1}=\sqrt{\frac{\varepsilon_{1}}{\mu_{1}}} / \cos \theta_{1},
\end{gathered}
$$

where

$\mathrm{k}_{21}$ is the coefficient of reflection from environment 1 surface;

$\mathrm{k}_{23}$ is the coefficient of reflection from environment 3 surface.

Directed Green functions for incident and reflected waves are written as follows:

$$
\begin{aligned}
\mathrm{G}_{1}=\frac{\mathrm{i}}{2 \pi} \int_{\mathrm{U}_{\operatorname{lmin}}}^{\mathrm{U}_{\operatorname{lmax}}} & \frac{\mathrm{F}_{1}(\theta)}{\sqrt{\mathrm{k}^{2}-\mathrm{U}_{1}^{2}}} \mathrm{e}^{\left\{\mathrm{i}\left(\mathrm{x}-\mathrm{x}_{0}\right) \sqrt{\mathrm{k}^{2}-\mathrm{U}_{1}^{2}}+\left[\mathrm{y}(\mathrm{x})-\mathrm{y}_{0}\right] \mathrm{U}_{1}\right\}} \mathrm{dU}_{1}+ \\
& +\frac{\mathrm{i}}{2 \pi} \mathrm{k}_{\mathrm{ompl}} \int_{\mathrm{U}_{\operatorname{lmin}}}^{\mathrm{U}_{\operatorname{lmax}}} \frac{\mathrm{F}_{1}(\theta)}{\sqrt{\mathrm{k}^{2}-\mathrm{U}_{1}^{2}}} \mathrm{e}^{\left\{\mathrm{i}\left(\mathrm{x}-\mathrm{x}_{0}\right) \sqrt{\mathrm{k}^{2}-\mathrm{U}_{1}^{2}}-\left[\mathrm{y}(\mathrm{x})-\mathrm{y}_{0}\right] \mathrm{U}_{1}\right\}} \mathrm{dU}_{1} .
\end{aligned}
$$

Expression (2) describes the behavior of incident and reflected waves near an ice layer.

\section{Results of mathematical modeling for RTTY regime.}

Table 1. Initial data

\begin{tabular}{|c|c|c|c|}
\hline Environment & $\begin{array}{c}\text { Frequency, } \\
\mathrm{Hz}\end{array}$ & $\begin{array}{c}\text { Dielectric permeability } \\
\varepsilon, \mathrm{F} / \mathrm{m}\end{array}$ & $\begin{array}{c}\text { Magnetic } \\
\text { permeability } \\
\mu, \mathrm{H} / \mathrm{m}\end{array}$ \\
\cline { 1 - 1 } Ice & \multirow{2}{*}{2150} & 3.25 & 1 \\
\cline { 1 - 1 } Air & 1 & 1 \\
\cline { 1 - 1 } Water & 81 & 1 \\
\hline
\end{tabular}

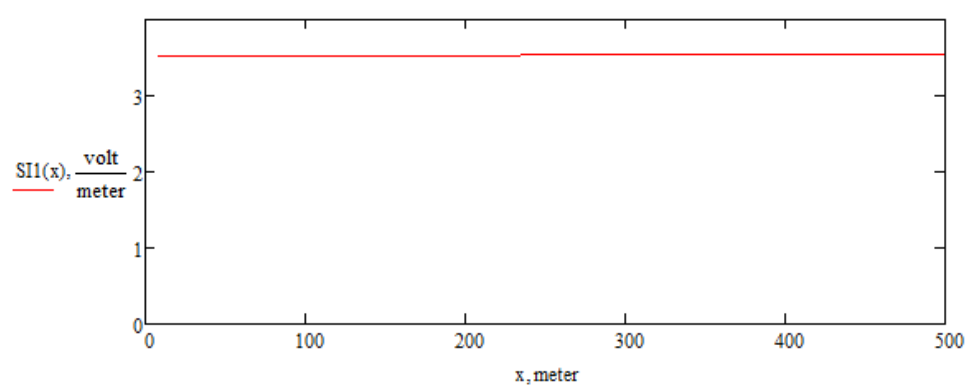

Fig. 2. Electric field strength inside an ice layer. 


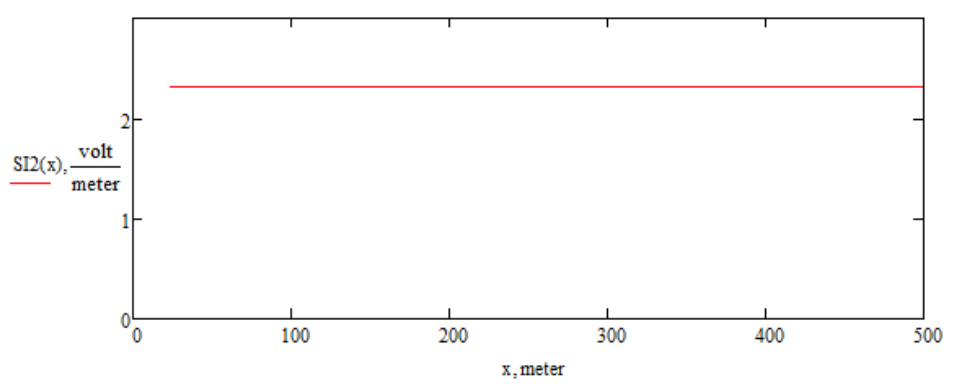

Fig. 3. Electric field strength near an ice layer.

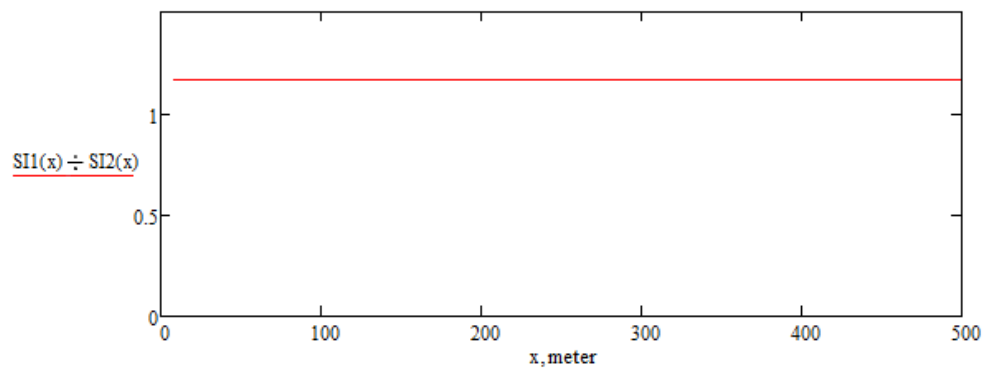

Fig. 4. The ratio of electric field amplitudes inside and near an ice layer.

The calculations show that electric field strength inside an ice layer is more than that near an ice layer.

\section{Results of mathematical modeling for AM regime}

Table 2. Initial data

\begin{tabular}{|c|c|c|c|}
\hline \multirow{2}{*}{ Environment } & \multirow{2}{*}{ Frequency, Hz } & $\begin{array}{c}\text { Dielectric permeability } \\
\varepsilon, \mathrm{F} / \mathrm{m}\end{array}$ & $\begin{array}{c}\text { Magnetic } \\
\text { permeability } \\
\mu, \mathrm{H} / \mathrm{m}\end{array}$ \\
\cline { 1 - 2 } Ice & \multirow{2}{*}{$28.5 \cdot 10^{6}$} & 3.25 & 1 \\
\cline { 1 - 1 } \cline { 4 - 4 } Air & 1 & 1 \\
\cline { 1 - 1 } Water & 81 & 1 \\
\hline
\end{tabular}

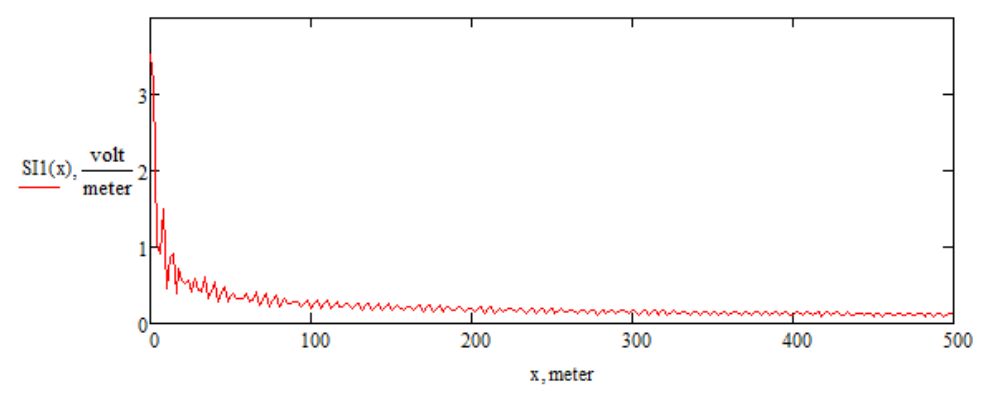

Fig. 5. Electric field strength inside an ice layer. 


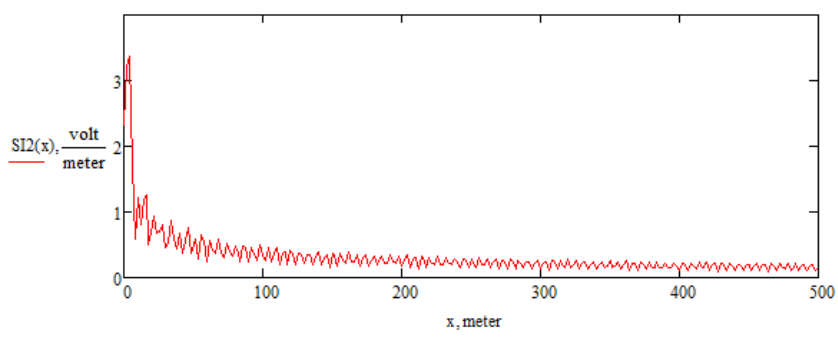

Fig. 6. Electric field strength near an ice layer.

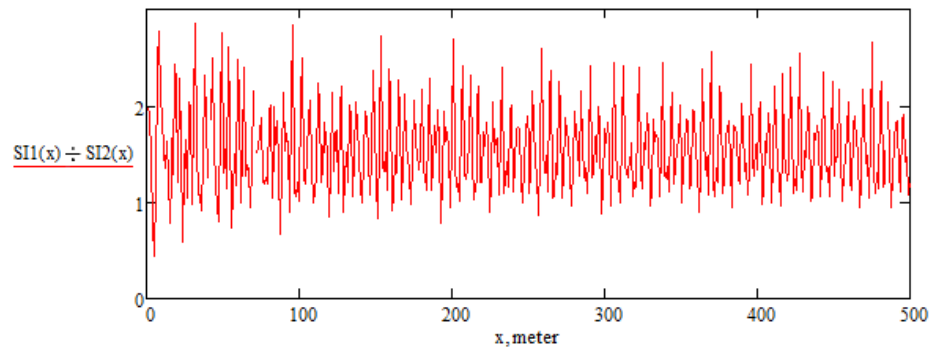

Fig. 7. The ratio of electric field amplitudes inside and near an ice layer.

It is clear from graphs 4 and 7 that amplitude of the electric field in an ice layer is about 1.5 times more than it's amplitude near ice layer.

\section{Aims and problems of experimental investigations}

The aim of the experiment was to confirm or to reject the hypothesis on signal amplitude increase due to the interferences of incident and reflected waves in an ice layer.

The main task of the experiment is to investigate the electromagnetic field strength:

1) near an ice layer formed in the result of interference of radiated and reflected cylindrical waves near an ice layer.

2) inside an ice layer formed in the result of interference of radiated and reflected cylindrical waves inside an ice layer.

In the course of the experiment we:

a) developed a method to measure the reflection coefficient of cylindrical electromagnetic waves by their intensity near an ice plane layer;

b) developed a method to measure the reflection coefficient of cylindrical electromagnetic ice waves from the «ice-water» and «ice-air» boundaries by their intensity inside the layer;

c) measured the dependence of electromagnetic wave intensity on the distance between a source and a receiver;

d) compared the signal levels near and inside an ice layer.

To investigate the processes of elastic wave propagation along the ice and water boundaries, the papers [1,3] suggested mathematical models based on directed Green functions. Experimental investigations of elastic wave propagation along two environments «ice-water» boundary allow us to refine ice parameters and initial conditions of mathematical models at the frequencies of several $\mathrm{kHz}$. 


\section{Electro hydraulic generator of elastic waves}

In order to generate an elastic wave at the boundary of water and ice, we constructed an experimental facility. It is illustrated in Fig. 8.

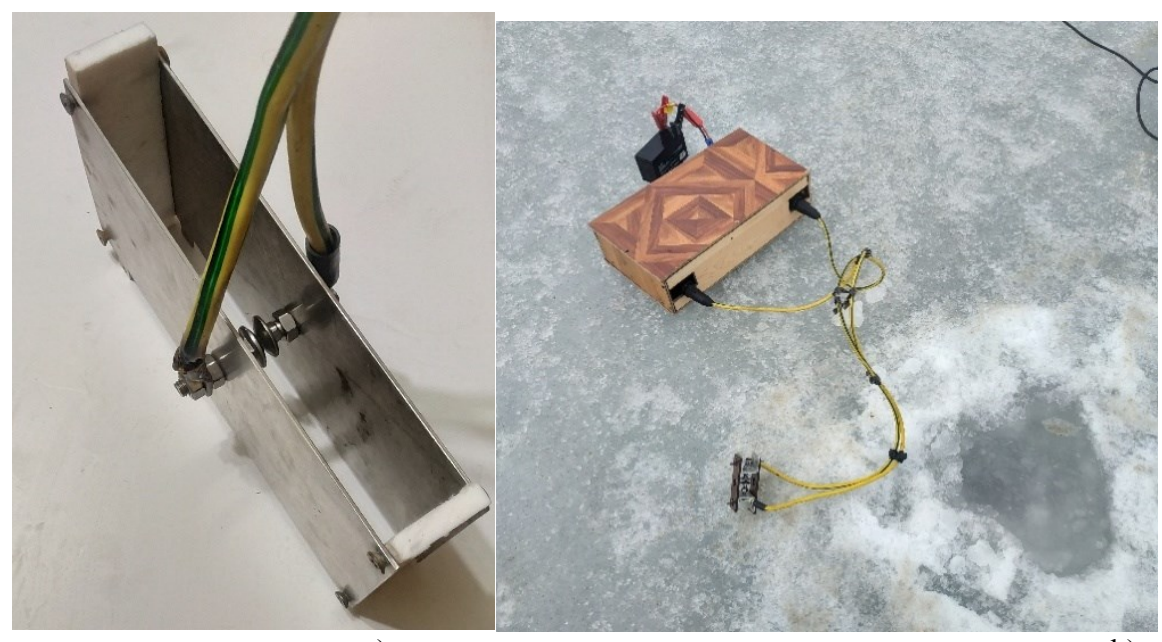

a)

b)

Fig. 8. Electro hydraulic generator: a) physical configuration of the unit; b) electro hydraulic radiator

Fig. 9 shows the functional scheme of an electro hydraulic generator working from an electric accumulator.

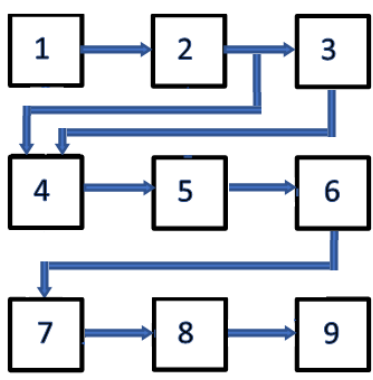

a)

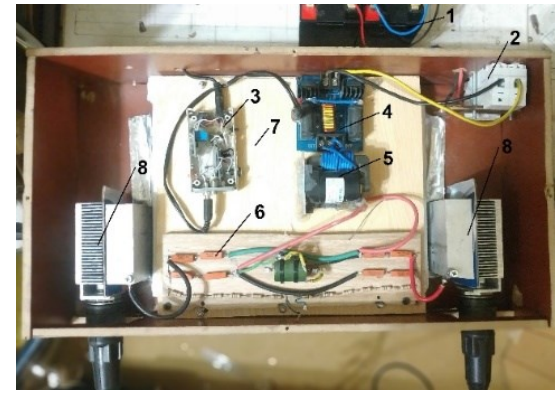

b)

Fig. 9. Functional scheme of elastic acoustic wave generation: a) functional scheme; b) physical configuration of the generator. 1 - accumulator; 2 - switch; 3 - control system; 4 - voltage converter; 5 - high-voltage transformer; 6 - rectifying element; 7 - storage capacitor; 8 - high-voltage discharger; 9 - electrodynamic radiator.

The complex for acoustic elastic wave generation operates as follows. Direct voltage of $24 \mathrm{~V}$ is applied from the accumulator 1 though the switch 2 to the control system 3 and voltage converter 4 . The control system is executed on a microcontroller and has a Bluetooth module to connect to a PC. Bluetooth connection allows us to set the pulse relative duration at electro hydraulic radiator 9 output in remote and in on-line regimes. Energy in a pulse depends on charge voltage of the storage capacitor $\left(C_{H}\right) 7$. Charge level of $C_{H}$ is defined by the change of gaps in the high-voltage dischargers 8 . Repetition frequency of pulse groups is limited by the time of complete discharging of $C_{H}$. The time of complete 
discharging of $\mathrm{CH}$ is determined by the resonance frequency and the quality of the discharge resistor circuit.

\section{Information and measuring system}

An information and measuring system (IMS) was developed for experimental check of the performance of the pulse electro hydraulic generator of elastic acoustic waves. Its functional scheme is illustrated in Fig. 10.
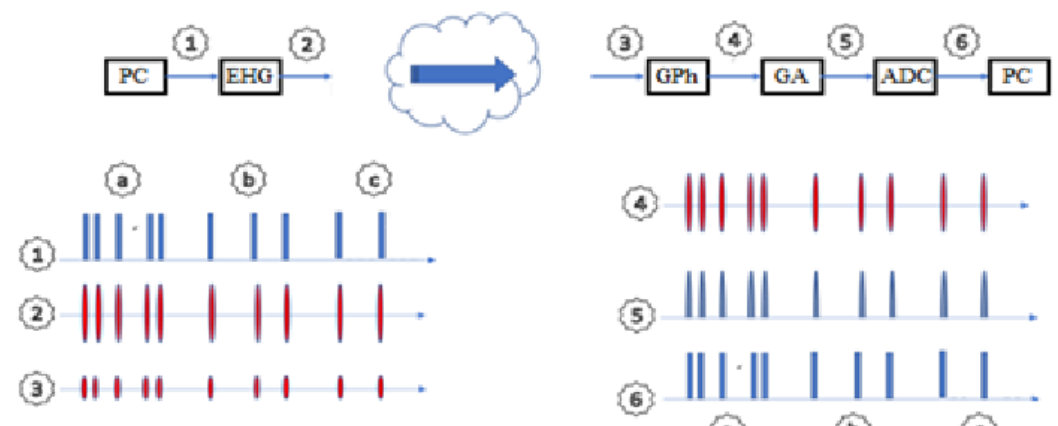

Fig.10. Functional scheme of the information and measuring system: PC - personal computer; EHG electro hydraulic generator; HPh - hydrophone; HA - hydrophone amplifier; ADC - analogue-todigital converter.

A hydrophone is submerged through another hole at a defined distance from the EHR. A gydroacoustic pulse is received by the hydrophone, is amplified by hydrophone amplifier, is converted into a digital code via the ADC and enters PC for data processing and display.

The IMS operates as follows. The EHG parameters, defining elastic wave pulse duration, are uploaded via Bluetooth connection by the help of a PC and serial input-output interface. The electric hydraulic radiator is submerged at an appropriate depth though a hole made in ice. The hydrophone is submerged through another hole at a defined distance from the EHG. A gydroacoustic pulse is received by the hydrophone $\mathrm{HPh}$, is amplified by hydrophone amplifier HA, is converted into a digital code via the ADC unit and enters PC for data processing and display.

\section{Conclusions}

It has been proved that signal electromagnetic wave intensity increases due to the interference phenomena in an ice layer based on mathematical modeling results.

Experimental investigations and the mathematical model of electro hydraulic generator showed the possibilities to apply them for physical modeling of propagation of elastic waves with shock excitation and frequency filling in water environments covered with ice and for data transfer for long distances in ice conditions.

All the measurements were carried out in Novik bay, near the Papenberg Island, Vladivostok.

\section{References}


1. Korochentsev V.I. Volnovye zadachi teorii napravlennykh i fokusiruyushchikh antenn [Wave problems of the theory of directed and focus antennas], monography,

Vladivostok: Dal'nauka, 1998. - 192 p. (in Russian)

2. Korchaka A.V., Em A.A., Korochentsev V.I. Vestnik inzhenernoy shkoly dal'nevostochnogo federal'nogo universiteta -- The Far Eastern Federal University: School of Engineering Bulletin, No. 1 (38), 2019. pp: 128-133. eISSN: 2227-6858 (in Russian)

3. Korochentsev V., Em A., Shpak Y., Xue W., Shabanov G. E3S Web Of Conferences2019г. c02013.

4. Cross J. D., Atkins P. R. IEEE transactions on anthennas and propagation, vol. 63, no 2, february 2015, p. 866-870.

5. Em A. A Korochentsev V.I., Korchaka A.V., Lobova T.Zh. electronic science journal Universum: technical sciences, No. 12(69), 2019. URL:

https://7universum.com/ru/tech/archive/item/8563

6. Brekhovskih L.M. Volny v sloistyh sredah. [Waves in layered media], monography, Moscow: Nauka, 1973. -340 p.

7. V.I. Korochencev, L.V. Gubko, M.V. Mironenko, I.V. Garasev. Nauchnotekhnicheskij i prikladnoj zhurnal «IZVESTIYA SFedU. ENGINEERING SCIENCES» - № 10 (183) - 2016 - p. 65-79. 